\section{Mania in Down's syndrome}

SIR: In the last couple of years a number of articles appeared claiming that mania does not occur in Down's syndrome (Journal, March 1985, 146, 319 320). However, quite the opposite can be postulated theoretically and is found in practice.

The biochemical basis for the induction of secondary mania is variable. In Down's syndrome a variety of endocrinological as well as neuropathological abnormalities are present which could precipitate secondary mania. One finds increased incidence of both head injury and epilepsy. A number of psychosocial factors also indicate that there should be an increased incidence of mania (e.g. higher parental age and higher social class). So, restricting one's line of argument to just reduced levels of catecholamines and indoles in Down's syndrome (Singh, 1988) is not particularly useful, even if these are considered as a final common pathway; also, drugs that bind to catecholamine or indole sites quickly do not lead to the altered mental state at the same speed.

The characteristic histology of dementia of Alzheimer's type is found in all people with Down's syndrome over the age of 30 years, and the hallmark neurotransmitter abnormality is a deficit in a cholinergic system of the brain. In Down's syndrome it manifests clinically as hypersensitivity to cholinomimetic agents (Sacks et al, 1989). Improvement following treatment of manic patients with cholinomimetic agent RS 86 in a double-blind study, has been shown to occur within days (Krieg et al, 1986), and thus one could suggest that a deficit in a cholinergic system is only one of the factors which predisposes people with Down's syndrome to develop mania at some stage.

The case notes of 27 Down's syndrome patients were examined and one case of recurrent mania was found.

Case report: The patient is a 46-year-old woman who, because she was an orphan with Down's syndrome, has spent her whole life in various institutions. Her personality was described as pleasant and friendly and she was conscientious at work. At the age of 32 years she had an episode of disturbed behaviour characterised by elevated mood ('smiling all the time'), decreased sleep ('up most of the night'), her speech becoming very loud and pressurised, and disinhibited behaviour (she took all her clothes off in front of the other patients and staff). She also became physically aggressive, lashing out at passers by and overturning tables and chairs in the dining room. The only abnormal belief that she had at that time was that she was pregnant. She was treated with neuroleptics and gradually over a period of two months returned to her previous level of functioning. There were three other almost identical episodes lasting several months which all responded to neuroleptics. There were no clear depressive episodes. Her general health was good apart from a couple of episodes of gastroenteritis. The following investigations were normal: full blood count, urea and electrolytes, chest X-ray, thyroid function tests and electroencephalogram (EEG). Although EEG was normal there were two reports from nursing staff that this patient had a grand mal seizure. As this seemed an isolated incident she was not treated with anti-epileptic medication. The attempts to reduce the maintenance medication of promazine: ( $100 \mathrm{mg}$ b.d.) to a lower dose resulted in a relapse of disturbed behaviour as described above. At present she is well on promazine ( $100 \mathrm{mg}$ b.d.) and orphenadrine (100 mg b.d.).

Kraepelin (1896) considered that "imbecility may form the bases for the development of other psychoses such as manic depressive insanity, the psychoses of involution and dementia praecox". This stance should be preserved and many cases of Down's syndrome could substantiate that this was hardly a simplistic view.

The London Hospital

Bisa HAEger

\title{
References
}

Kraepelin, E. (1896) Psychiatrie. (transl. by A. R. Defendorf, 1902). New York.

KRIEG, J. C. \& BERGER, M. (1986) Treatment of mania with the cholinomimetic agent RS 86. British Journal of Psychiatry, 148, 613.

SACKS, B. \& SMITH, S. (1989) People with Down's syndrome can be distinguished on the basis of cholinergic dysfunction. Journal of Neurology, Neurosurgery and Psychiatry, 52, 1294.

SingH, I. (1988) Down's syndrome with mania. British Journal of Psychiatry, 152, 436-437.

\section{Mania complicating ECT}

SIR: There are several reports of euphoric and hyperactive states following electroconvulsive therapy (ECT). These range in duration from minutes (Sackeim et al, 1983) to at least several days (Lewis \& Nasrallah, 1986), and vary in the degree of associated cognitive impairment (Devanand et al, 1988). Mitigating factors may include a personal history of mania (DeQuardo \& Tandon, 1988), the locus of application used (Sackeim et al, 1983), and concomitant use of antimanic medication (DeQuardo \& Tandon, 1988). Persistent symptoms have been treated medically (Devanand et al, 1988). Without providing details, Barrett (Journal, April 1989, 154, 575) reports that his practice is to continue a course of ECT in spite of emerging manic symptoms, viewing such complications as representing affective disorder "modified rather than fully treated". The following is otherwise the first reported case in 